thesis in form of a scientific paper. Throughout the process, they are accompanied by a tutor.

Results Since its beginning in 2012, the number of participants in the program is stable with 10-12 students/year. All of them are $\mathrm{OSH}$ experts with at least 2 years of experience in the field coming from eight Latin American countries. Students evaluate the project-based learning approach as positive. Of the 43 graduating students, 9 research papers were published in journals. More than half of the graduates teach students at local universities and thereby act as multipliers. Few continue to carry out research mainly due to lack of priority in their home countries.

Discussion The project-based learning approach contributes to occupational health research in Latin America. The concept might be promising also for other LMIC. However, due to the individual tutoring the program is cost intensive, publication of the results challenging and work opportunities for researchers limited.

\section{FINANCIAL IMPACT OF MEDICAL TESTS REDUCTION FOR THE OCCUPATIONAL HEALTH DEPARTMENT OF A COMPANY IN TIMES OF CRISIS}

${ }^{1}$ FS Almeida*, ${ }^{1}$ RMC Almeida, ${ }^{2} \mathrm{CG}$ Oliveira, ${ }^{3} \mathrm{SE}$ Takada. ${ }^{1}$ Occupational Physician of Tejofran Group, São Paulo, Brazil; '2Occupational Nurse of Tejofran Group, São Paulo, Brazil; ${ }^{3}$ Occupational Physician of Toniolo and Busnello Túneis e Terraplanagem e Pavimentações, São Paulo, Brazil

\subsection{6/oemed-2018-ICOHabstracts.876}

Introduction Due to the severe crisis that Brazil is facing in recent years, companies have been forced to implement cost control programs trying to mitigate impact of economic recession.

Knowing that the Occupational Health Department is responsible for raising company costs due to large number of medical tests regularly requested, one way to cut down expenditures would be to revise pre-established internal protocols that vary according to job characteristics of the company.

This study shows the financial impact when removing unnecessary complementary medical tests from Tejofran's internal protocols, an outsourcing services company in Brazil, without interfering in the worker's health.

Methods Reviews were made to the company's internal protocols and, based on the medical literature, complementary tests which are not required by law and do not influence in the worker's health, were excluded. Some protocols could not be revised due to request of partner companies. The amount spent in 2016 was compared with the expenditures after the changes in 2017, considering the same costs of tests from previous years for the same group of workers to estimate the obtained savings.

Results 5029 exams were excluded, the main ones: Audiometry (32\%), Electrocardiogram (14\%), Electroencephalogram $(14 \%)$ and Blood Sugar (14\%). A reduction of R\$ 106.050,36 $(58,6 \%)$ from total value incurred, comparing to previous year. This amount saved could be invested in other action plas that benefit workers like physical workplace exercise, awareness campaigns and trainings.

Conclusion This study shows that it is possible to reduce expenditures with company's Occupational Health Department without having to reduce benefits for employees and without harming the health of workers, and the department's main objective. The amount saved can be invested in action programs aiming improvement of life quality for employees and reducing rates of work accidents, absenteeism, and fatalities, therefore reducing costs for the company.

\section{PRACTICES IN THE RAILWAY INDUSTRY FOR ASSESSMENTS, INTERVENTION AND MANAGEMENT OF PSYCHOSOCIAL ISSUES IN SOUTH AFRICA}

M Bester*. Bombela Operating Company, Johannesburg, South Africa

\subsection{6/oemed-2018-ICOHabstracts.877}

Introduction There are a number of psychosocial issues prevalent in the rail industry that influence workers' health and wellbeing. Managing psychosocial risks is a legal imperative that oblige employers to establish processes in accordance with national legislation to match task and environments to the physical and psychological capabilities of people to safeguard their health and wellbeing. Globalisation, higher workload and more pressure, increased job insecurity as well as poor work life balance contribute to these psychosocial issues. Methods An analysis of questionnaire responses from Occupational health practitioners working in the railway industry, to describe types of assessments, various interventions and management of workers with psychosocial issues were conducted. Consideration were given to reason for consultation, followups, and referrals to secondary psychological interventions where indicated.

Result The results revealed that we are lacking information that could provide insight into the magnitude of the problem that can influence policies and practices in the workplace. Effective solutions is needed for the prevention of psychosocial risks as these offer good returns in improved efficiency and productivity, better health, reduced absenteeism and lower medical costs.

Discussion It is widely acknowledged that work and life related stress is very common and has a high cost in terms of workers health, absenteeism and lower performance in the workplace. The development of effective guidelines, processes and policies is important to assist occupational health practitioners in assisting workers to get expert advice and referral at point of service to deal with psychosocial issues.

Conclusion A comprehensive approach by practitioners and new patterns of prevention is necessary to face current psychosocial issues in the workplace. It proved repeatedly that effective solutions should exist for the prevention of psychosocial issues as this offer good return in terms of reduced absenteeism, better health, improved work efficiency and productivity.

\section{RETROSPECTIVE STUDY OF THE PROFILE OF BRAZILIAN PROFESSIONAL DRIVERS RECEIVING SICK LEAVE BENEFIT}

VR Batalini*, RV Brito, LFT Priester, IC Nascimento, LR Ferreira. Centro Universitário das Faculdades Associadas de Ensino - UNIFAE, São João da Boa Vista, Brazil

\subsection{6/oemed-2018-ICOHabstracts.878}

Introduction The health condition of professional drivers is one of the factors playing a role in assuring traffic safety. Therefore, it is essential the assessment of the profile of the drivers receiving sick leave benefits as well as the pathologies 
occurring in this occupational group. This study aimed to assess the profile of professional drivers receiving sick leave benefits from the Brazilian National Institute of Social Security (INSS).

Methods This was a cross-sectional study involving 120 professional drivers receiving temporary sick leave benefits from INSS. The drivers were evaluated from November 2014 until December 2015 and submitted to a structured analysis for data collection including: gender, age, type of vehicle driving, driver's license type, ICD-10, absenteeism time, presence of chronic disability and current employment status.

Results The results showed that all drivers were male having a mean age of 54 years-old ranging from 24 to 71 years-old; truck drivers represented 47\%, bus drivers (27\%), and drivers of others vehicles (26\%), being mostly category D (68\%) and category E (20\%). Trough ICD-10, the study revealed the most affected diseases were cardiovascular (31\%) and musculoskeletal diseases (29\%). The mean absenteeism time was 62 days and 8\% developed chronic disability, 90\% kept the same post, accommodation was necessary in $8 \%$ of the cases, and $2 \%$ had disability retirement.

Discussion From these results, it is concluded that most professional drivers receiving sick leave benefits from INSS were adult males, category D truck drivers, presenting mainly with cardiovascular and orthopaedic diseases, absent from work for two months and some associated with chronic impairment. The results provide some evidence that Brazilian professional drivers are at risk for developing certain diseases. These data also should help companies to take measures for preventing work time loss and disability caused by these diseases, including for example health promotion.

\section{SICK LEAVE BY OCCUPATIONAL ACCIDENT: A RETROSPECTIVE EPIDEMIOLOGICAL STUDY}

RV Brito*, VR Batalini, AFA Lemos, AES Zafalon, CM Galhardi, LR Ferreira. Centro Universitário das Faculdades Associadas de Ensino - UNIFAE, São João da Boa Vista, Brazil

\subsection{6/oemed-2018-ICOHabstracts.879}

Introduction Wounds, illness and deaths caused in the work environment cost $\$ 21,46$ billion (2015) in Brazil, according to the Secretariat of Labour Inspection of Ministry of Labour. Contributing to this overview, the Sick Leave is a benefit granted by Brazilian National Social Security Institute (INSS), to workers who are victims of occupational accidents and become temporarily unable for work. In this context, the present study aims to evaluate the epidemiological profile of workers receiving sick leave by occupational accident, correlating data about illnesses, gender, occupational location and age group.

Methods A retrospective study based on analyses of 4.035 patients who requested sick leave by occupational accident from the Brazilian National Social Security Institute (INSS), characterising the age, gender, prevalence of urban and rural workers, more prevalent diseases associated with the occupational accidents through the ICD-10, from January 2014 to March 2017.

Results The study showed that the majority of 4.035 victims of the accidents with the benefit were male $(73,08 \%)$, associated with urban jobs (91,82\%) ranging from 30-39 years-old $(28,52 \%)$; rural jobs represented $8,17 \%$ ranging from $45-$ 54 years-old. The fractures of upper limb represented 25,41\% of all benefits, followed by fractures of lower limb $(18,33 \%)$, diseases of upper limb not associated with fractures $(12,48 \%)$ and diseases of lower limb not associated with fractures (6,16\%).

Discussion The profile of workers who were victims of occupational accidents that received disability benefits from INSS revealed that the majority of beneficiaries were male adults, working in urban jobs ranging from 30-39 years-old, associated mainly with diseases of upper limbs. These data should help in the implementation of measures to prevent the loss of work capacity caused by occupational accidents involving Brazilian workers. It's expected this prevent measures decrease the costs related to work environment.

\section{BRAZILIAN SUPERIOR LABOUR COURT AND THE RESPONSIBILITY OF THE EMPLOYER FOR ACCIDENT OR OCCUPATIONAL DISEASE: PREVENTIVE AND REPARATORY ACTIONS}

${ }^{1}$ SR Cavalcante*, ${ }^{1}$ RAG Vilela, ${ }^{2} \mathrm{GG}$ Feliciano. ${ }^{1}$ University of São Paulo - School of Public Health, São Paulo, Brazil; ' ${ }^{2}$ nniversity of São Paulo - School of Law, São Paulo, Brazil

\subsection{6/oemed-2018-ICOHabstracts.880}

Introduction Brazil developed regulatory system and institutional structure to protect workers health and safety in the workplace. However, acidentes and diseases ocurrences remain high and great distance exists between legislation and voluntary law compliance. Brazilian laws provide procedural instruments to compensate the damage caused to workers health and to prevent future injuries. This survey verified how Brazilian Labour Judiciary are judging the actions regarding the companies liability in diseases and accidents at work, including the convictions values.

Methods Decisions published in 2015 that judged work-related accidents and diseases (individual and collective actions) were analysed consulting online Brazilian Superior Labour Court (TST) jurisprudence database. Data categorization was done considering the result (court application rejected or accepted), reasoning used by the judges and the compensation amount.

Result Labour High Court issued 231799 decisions in 2015, with $6.76 \%$ about work accidents and $0.12 \%$ on collective action and work accidents. The processes have been filed by Labour Prosecutor (83\%) and Unions (17\%). The compensation for collective moral damage had average of US\$73 530 . In individual reparatory actions, the employer had to compensate for worker health damage in $90 \%$ of cases, with high degree of sentences reformed (41\% to increase/deny and $4 \%$ to extinguish/reduce arbitrated values). The values arbitrated were between US\$65 000 and US\$1 32000 (fatal acidentes) and US\$4400 to US\$53000 (occupational diseases and other acidentes).

Discussion Although collective actions are little used, the labour judicial system provides the preventive protection requested: all judgments analysed granted compensation for collective moral damage and/or obligation to make changes to improve prevention and safety. The values of convictions arbitrated in collective actions are significant and indicate social and economic repercussions, stimulating employers to improve their companies working environment conditions. It is necessary to intensify the use of collective actions, because they are more efficient for prevention than reparatory individual lawsuits. 